\title{
SEMBLANZA
}

\section{El profesor Luis Ángel Rojo Duque}

\section{Adolfo Rodero Franganillo}

La muerte de Luis Ángel Rojo ha provocado numerosos comentarios, como es lógico en relación con una figura pública de su importancia; es significativo que todos los escritos muestren una alta valoración y aprecio de su persona. ¿̇Se trata de los acostumbrados elogios que se expresan a la muerte de alguien? Creo que no; el tono de los elogios me hace pensar que son sinceros, lo que, por otra parte, coincide con mi opinión sobre Rojo.

Se han publicado numerosas biografías; no pretendo escribir una más, en la que poco podría añadir que no se haya dicho ya. Me limitaré entonces a subrayar aquellos aspectos que desde mi punto de vista tienen más relevancia:

- Como gobernador o subgobernador del Banco de España, le tocó enfrentarse a dos problemas delicados: la sustitución de Mariano Rubio, el anterior gobernador, que fue objeto de un proceso, y la expropiación de BANESTO. Con relación al caso de $M$. Rubio mantuvo una postura muy discreta lo que facilitó su acceso al cargo.

- Tuvo un papel relevante en la elaboración de la Ley de Autonomía del Banco de España, que determinó la homologación del banco central español con los de los países desarrollados.

- Entre sus "especialidades", que comentaremos a continuación, destaca su dominio de la política monetaria que aplicó a la economía española, modernizando una política que anteriormente habría que calificar de "tosca" y altamente politizada. En este terreno, la creación de las provisiones anticíclicas del sector bancario, criticadas en su momento, permitieron que la banca española superara los primeros efectos de la crisis en mejor situación que la banca de otros países. 
- El momento más importante de su responsabilidad como gobernador del Banco fue el de la incorporación de España a la Unión Monetaria. La sustitución de la peseta por el euro, con sus luces y sus sombras, ha sido un hecho trascendental para la economía española, de cuyo proceso Rojo fue uno de los principales protagonistas. Consecuencia de ello fue su participación en el Consejo de Gobierno del Banco Central Europeo, en el que tuvo un papel muy relevante.

- Rojo no quiso participar nunca, de forma directa, en las contiendas políticas; fue un científico y un funcionario que asesoró a gobiernos de distinto signo político, sugiriendo y proponiendo las medidas políticas que necesitaba el país (esto fue especialmente importante en los primeros gobiernos de la democracia: los de Adolfo Suárez, Leopoldo Calvo-Sotelo y Felipe González).

- Un reciente libro de artículos suyos, incluía el texto sobre Galdós que expuso cuando ingresó en la Real Academia. Fue una agradable sorpresa que me confirmó que Rojo no sólo era un excepcional economista, sino también un humanista en el sentido clásico de la palabra.

Me gustaría detenerme a continuación en su faceta de profesor. Para los que quedamos de los que estudiamos en la Facultad de Económicas del viejo caserón de San Bernardo y también para muchos economistas más recientes, Rojo será siempre el "maestro", el "profesor"; esta denominación, con que tantas personas se refieren a él, muestra el importante papel que tuvo en la universidad española. En su formación tuvo un papel esencial la London School of Economics que le puso en contacto con autores e ideas que destacaban en el mundo económico anglosajón de mediados del siglo XX y que no eran demasiado conocidos en España. Se incorporó después a una Facultad que reunía un plantel de economistas excepcional: Fuentes Quintana, Sampedro, Figueroa, Varela, Velarde y otros muchos; los estudiantes de entonces tuvieron/tuvimos la suerte de contar con el magisterio de este cuadro de docentes. Rojo enseñó Macroeconomía, pero no se limitó a impartir unas buenas clases; desde el primer momento, formó o participó en este grupo que quería impartir una enseñanza de calidad; por ejemplo: el programa de doctorado era anteriormente un trámite rutinario; este grupo creó un programa de doctorado de calidad, una auténtica especialización en las nuevas teorías económicas (una anécdota en este sentido: como en España apenas se contaba con la bibliografía más importante, buscaron una financiación empresarial para poder repartir entre los doctorandos fotocopias de los artículos y textos, en inglés por supuesto, de primer nivel). Como es lógico su actividad académica se completó con la publicación de originales: sus apuntes de teoría económica, un auténtico libro sobre el tema y muchos otros libros, entre los que nos limitaremos 
a destacar el excelente Renta, precios y balanza de pagos. Por otra parte, ¿̇cuáles fueron las teorías que formaron parte de su pensamiento? Se podría que, durante los años cincuenta y sesenta del pasado siglo, Rojo era un keynesiano, pero a lo largo de los años siguientes su postura fue evolucionando, incorporando a ese trasfondo teórico lo más aprovechable de las ideas que iban surgiendo en el campo de la teoría económica; Rojo no era un keynesiano "puro" pero menos aún un liberal ni tampoco un neoclásico; repetimos que hizo una síntesis de las ideas más importantes de la segunda mitad del siglo XX; ciertamente no fue un creador de nuevas teorías pero aportó una visión completa y elaborada de la economía de estos años.

Finalmente, quisiera añadir unas líneas sobre mis recuerdos personales del "profesor". Conocí personalmente a Rojo cuando codirigió con Jaime Loring, en ETEA, el coloquio sobre los problemas del desarrollo regional, en 1968 (entre paréntesis, coloquio que despertó grandes recelos entre las autoridades del régimen, provocando problemas incluso policiales); aunque yo no formaba parte de ningún grupo de la Facultad, en ese momento, estaba cursando el programa de doctorado; le expuse mi dificultad para asistir a las sesiones de seminario y me dio toda clase de facilidades; de acuerdo con su propuesta me trasladé a Madrid durante aquel verano; me facilitó todo el material que utilizaban y que yo debía leer y comentar con él; me atendió en numerosas ocasiones durante aquellos meses, superando finalmente el programa que había creado aquel grupo; después accedió a dirigir mi investigación de doctorado, cuya tesis presenté en la Universidad Complutense, ante un tribunal formado por algunos de los profesores citados. Más adelante quise profundizar en los problemas del sistema monetario internacional; como es lógico el Banco de España tenía la información más completa sobre el tema; Rojo que era entonces director del Servicio de Estudios del Banco me dio toda clase de facilidades, hice frecuentes visitas al Servicio para leer la documentación sobre el citado sistema, visitas que terminaban siempre con una entrevista en la que comentábamos los "papeles", aclarándome todos los aspectos que él dominaba dada su actividad profesional. Posteriormente nuestros contactos han sido más esporádicos: coincidencia en algunos actos académicos y ciertas comunicaciones postales. Termino ya reafirmando que siempre lo recordaré como el "maestro". Descanse en paz. 